\title{
Evaluation of the Technical and Economic Feasibility of Mixed Grade Cores in Transformer Design According to EN50588-1
}

\author{
Mehmet Aytac CINAR
}

\begin{abstract}
Permissible maximum no-load and load losses of distribution transformers are given in EN50588-1 regulation. The main parameter in transformer design, which affects the core loss of a transformer, is core grade. Selecting the superior grades, which have better electromagnetic performance, transformer no-load losses could be minimized. However, such grades increase the cost of core. In this study, ability of designing distribution transformers, which correspond to the loss classes given in EN505881 , is investigated using eleven different core steels. Then mixed graded core constructions are evaluated to minimize the core material cost, by means of technical and economical manner. Analytically calculated parameters of designed mixed graded transformer are investigated and verified by both electromagnetic simulations using finite element method and experimental tests of manufactured prototype transformer. Considering the current specific costs of different grades, core costs of mixed cores were calculated as $28,2 \% ; 4,45 \%$ and $7,81 \%$ lower than the reference single graded cores for A0, AA0 and AAA0 loss classes, respectively.
\end{abstract}

Keywords: cost; distribution transformer; EN50588-1; mixed grade core

\section{INTRODUCTION}

Transformers are one of the main components of power transmission and distribution system and are responsible of a great portion of the power losses that occur in the grid. These losses are resolved into two components, no-load losses and load losses. Nowadays, with the EN50588-1:2017 regulation, the permissible no-load and load losses of distribution transformers are given depending on the power and voltage level of the transformer.

In order to increase the operating efficiency of the transformer, determining the loss-making components and minimizing these losses efficiently are important issues for the designers. No load losses, which occur while the transformer is energized, are particularly important. As well as the design parameters and core manufacturing methods, selected core materials have an important effect on the no load loss value of a transformer. In addition, manufacturing cost is also another important parameter that should be considered in design stage. Although the initial purchase cost is generally taken into consideration by consumers, the operating costs that will occur during the expected life of the transformer and which are directly related to the loss classes should also be evaluated.

In the design stage, a single material type is conventionally preferred in core structure. However, it is known that different material types are used together in cases where the manufacturing cost desired to be reduced or the target limit loss value cannot be achieved as a result of design mistakes, by manufacturers. In literature, there are many research studies where different material types were used by mixing in the transformer core.

The mixed core structure, in which two or more types of materials are used together, was first announced in literature in 1929. With these patents, it is recommended to use silicone-based materials and iron-nickel alloy materials together. In these studies, the inner parts of the core are manufactured using low-loss material with a high permeability value, and higher-loss materials are used on the outer parts. Thus, it has been demonstrated that the permeability of the core increases and it is possible to reduce the core losses [1-3]. In [4], the use of oriented and non-oriented types of steels are examined and it is stated that the core losses as well as core costs could be reduced.

In $[5,6]$, analyses and experimental studies for the use of different core material types in measurement transformers are presented. In these studies, 2 - $8 \mathrm{VA}$ measurement transformers were used and the effects on the accuracy levels of the toroidal core transformers were evaluated.

In [7], a $25 \mathrm{kVA}, 11 / 0,425 \mathrm{kV}$ transformer which was manufactured by combining traditional material types and amorphous materials was examined and core losses and cost were evaluated. Similarly, in $[8,9]$, it was emphasized that amorphous materials were proved to have positive effects on transformer losses and efficiency, but additional structural components were required, especially with the increase in dimensions of the transformer. For this reason, it is seen that conventional core materials and core production methods maintain their advantages in transformers for high power levels.

In [10], the effects of mixed core structure on power losses and core temperature for a 10 MVA, 69/13,8 kV single phase core type transformer, are examined. Here, combination of four different core materials (M3, M4, M5, M6) and a low loss core material type (H0) in different ratios, were evaluated. It is concluded that in order to avoid saturation effects in the mixed core structure, it is enough to perform the core design at 1,6 $\mathrm{T}$ and to use the low loss material in the inner one third part of the core.

In $[11,12]$, the flux distribution for single and three phase wound core transformers, are examined. The wounded core is divided into three parts, by means of the determined flux accumulation on the core section. It has been stated that the total cost is reduced by using low loss material in the interior of the core, where the flux density is higher.

In the studies conducted in $[13,15]$, it is stated that the core losses could be reduced by up to $35 \%$, by preferring core materials with low lamination thickness and improved laser application.

It is observed that, in almost all the studies in literature, the wound core structure was examined. With this core construction, core losses could be reduced by about $15 \%$ compared to the stacked core structure. Today, it is known 
that the wound core structure can be applied technically up to 5 MVA power level. However, due to the wound core manufacturing costs are higher, multistep lap stacked core construction in distribution level is still predominant $[16$, 17].

In this study, production of distribution transformer with mixed core structure is evaluated technically and economically for each loss class specified in EN50588-1 standard. For this purpose, mixed core designs were performed numerically using eleven different core materials for a $400 \mathrm{kVA}, 34,5 / 0,4 \mathrm{kV}, 50 \mathrm{~Hz}$ distribution transformer and occurred power losses as well as electromagnetic parameters were calculated by electromagnetic analyses. Then, obtained results were verified by laboratory tests of manufactured prototype transformer.

\section{CORE LOSSES}

The relationship between design parameters of transformers is given as

$E=4,44 N B_{m} f A$

where, $E$ is the grid voltage and $B_{m}, N, f$ and $A$ are the maximum flux density, the number of turns per phase, the grid frequency and the core cross section area, respectively. Here, the maximum flux density and the core cross section area are inversely proportional, if the number of turns per phase was kept constant.

General specific core loss equation is given as:

$P_{\text {total }}=P_{h}+P_{e}+P_{i}$

under sinusoidal excitation. Here, $P_{h}$ is hysteresis loss, $P_{e}$ is classical eddy current loss and $P_{i}$ is excess loss components of total power loss, respectively. These three components are expressed as a function of core induction and grid frequency, as:

$$
\begin{aligned}
& P_{h}=k_{h} f B^{n} \\
& P_{e}=k_{e} f^{2} B^{2} \\
& P_{i}=k_{i} f^{1.5} B^{1.5}
\end{aligned}
$$

In these equations, $k_{h}$ is hysteresis loss coefficient, $k_{e}$ is eddy current loss coefficient and $k_{i}$ is excess loss coefficient, respectively. In addition, $\mathrm{n}$ is called Steinmetz coefficient and varies between 1,6 and 2, in literature. Literature studies show that $1 \%$ rise of $B$ causes a $2 \%$ rise of the losses [18].

Hysteresis, classical eddy current and excess loss coefficients are expressed as:

$$
\begin{aligned}
& k_{h}=\frac{\pi}{\rho} \cdot \frac{H_{i r r}}{B_{p}} \\
& k_{e}=\frac{\pi \sigma d^{2}}{6 \rho}
\end{aligned}
$$

$k_{i}=7,87 \sqrt{\sigma G V_{0} S}$

Respectively [19-21]. Here, $H_{\text {irr }}$ is the positive field strength value which corresponds to the $B=0$ point of the hysteresis curve of the material, $\sigma$ is electrical conductivity, $d$ is lamination thickness, $\rho$ is mass density of the material, $S$ is cross section of the lamination, $G$ is a constant and $V_{0}$ is also a constant which depends on the micro structure of the material.

As given in Eq. (3) to Eq. (8), core losses directly depend on the physical and electromagnetic features of the core material, as well as frequency and core induction. Therefore, selecting superior core grades which have lower specific losses and lower thicknesses, is the main solution to reduce core losses in the design stage of transformers.

\section{DESIGN STAGES OF MIXED GRADE CORE}

For each loss class, specified in the EN50588-1 standard, it is aimed to minimize the cost with designed mixed core structures. For this purpose, first, the core costs were determined by performing the core designs that meet the requirements of the loss classes for each material type. By comparing the obtained results, it is possible to determine the advantage of the mixed core structure.

Most widely preferred core materials in conventional power and distribution transformer manufacturing are $\mathrm{M}$ grade grain-oriented core steels. These steels are classified as M2, M3, M4, M5 and M6 types, according to AISI (American Iron and Steel Institute) notification. Here, M stands for magnetic material and the following number expresses the core loss degree of that steel type. According to this notification, specific core loss of M6 steel, which has a thickness of $0,35 \mathrm{~mm}$, is $0,968 \mathrm{~W} / \mathrm{kg}$ for the induction value of $1,5 \mathrm{~T}$ in $50 \mathrm{~Hz}$. However, M2 steel lamination is $0,18 \mathrm{~mm}$ thick and causes $0,648 \mathrm{~W} / \mathrm{kg}$ specific loss for the induction of 1,5 $\mathrm{T}$ in $50 \mathrm{~Hz}$ [22]. Otherwise, $\mathrm{H}$ grade steels, which have higher permeabilities and superior magnetic properties compared to $\mathrm{M}$ grades, provide lower specific core loss values and less noise structures [23]. Reducing core losses up to $10 \%$ could be possible by preferring this grade [24]. H-DR grade steels, which are manufactured by applying laser scribing process to $\mathrm{H}$ grades, have improved domain structures resulting lower eddy current losses in transformer core.

In this study, 11 steel types (M2, M3, M4, M5, M6, $\mathrm{H} 0, \mathrm{H} 1, \mathrm{H} 2, \mathrm{H} 0-\mathrm{DR}, \mathrm{H} 1-\mathrm{DR}, \mathrm{H} 2-\mathrm{DR})$ of totally three different grades (M, H and $\mathrm{H}-\mathrm{DR})$ were investigated and their effects on core losses were evaluated. In design stage, 20 different core designs between $0,25 \mathrm{~T}$ and 1,90 T, were made. With these designs, it was aimed to define how the loss requirements of $\mathrm{A} 0, \mathrm{AA} 0$ and $\mathrm{AAA} 0$ classes could be met.

In core shape calculations, core cross section was designed with seven layers and the calculated layer angles $\left(\alpha_{1}, \alpha_{2}, \ldots \alpha_{7}\right)$ were used in common for all 20 core designs. While calculating the effective core cross section areas and core inductions, stacking factors of each core material were also considered.

Schematic of core cross section and layer angles are shown in Fig. 1. 


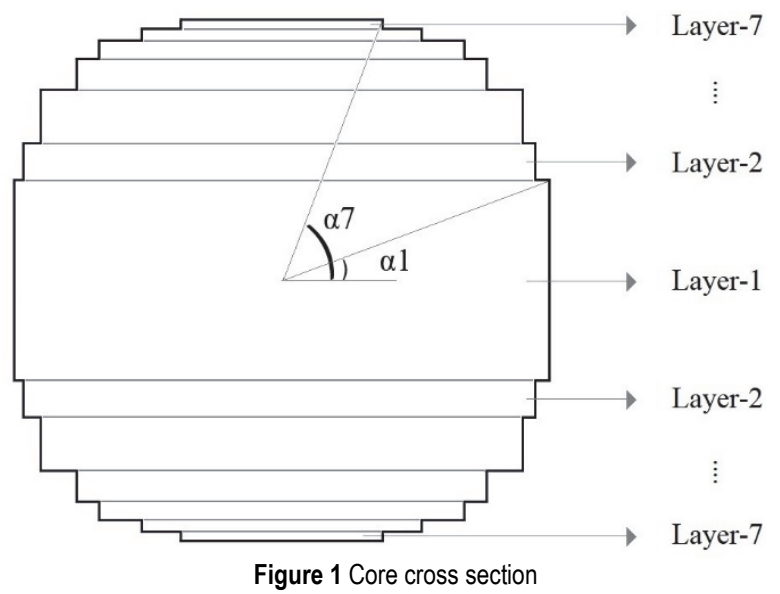

In addition to the core cross section area, primary and secondary winding dimensions were re-calculated for each core design, to obtain the required short circuit reactance values [25]. Copper materials were used in low voltage and high voltage windings design.

According to EN50588-1 regulation, allowed maximum core loss values of a $400 \mathrm{kVA}, 34,5 / 0,4 \mathrm{kV}$ transformer are specified as $516 \mathrm{~W}, 464,4 \mathrm{~W}$ and $264 \mathrm{~W}$ for A0, AA0 and AAA0 loss classes, respectively [26]. For all studied transformer designs, calculated load loss is less than the limit value of Ak loss class.

Calculated core losses vs. core induction curves for studied steel types are given in Fig. 2 to Fig. 4, respectively. Maximum core loss values of A0, AA0 and AAA0 classes are also given in these figures.

Considering the results, it would be possible to evaluate the design feasibility of transformer cores, which meet the maximum loss limits given in EN50588-1, using different steels. Among investigated steel types, M5 steel, which has $0,35 \mathrm{~mm}$ thickness, is the most widely used material in transformer core manufacturing. Calculated loss values for M5 steel show that the limit values of noload losses for A0, AA0 and AAA0 classes have been obtained for core inductions of $0,89 \mathrm{~T}, 0,76 \mathrm{~T}$ and $0,27 \mathrm{~T}$, respectively. M2 steel, which has a thickness of $0,18 \mathrm{~mm}$, gives the best results among $M$ grades. Using this steel type, core inductions were calculated as $1,31 \mathrm{~T}, 1,18 \mathrm{~T}$ and $0,54 \mathrm{~T}$, to meet the limits of loss classes expressed above, respectively. According to Eq. (1), it is obvious that the higher induction value provides a more compact core design. Among investigated materials, M6 steel, which is the thickest lamination, has the highest specific core loss. As a result of that, core induction should be decreased to $0,18 \mathrm{~T}$, to meet the requirement of AAA0 loss class.

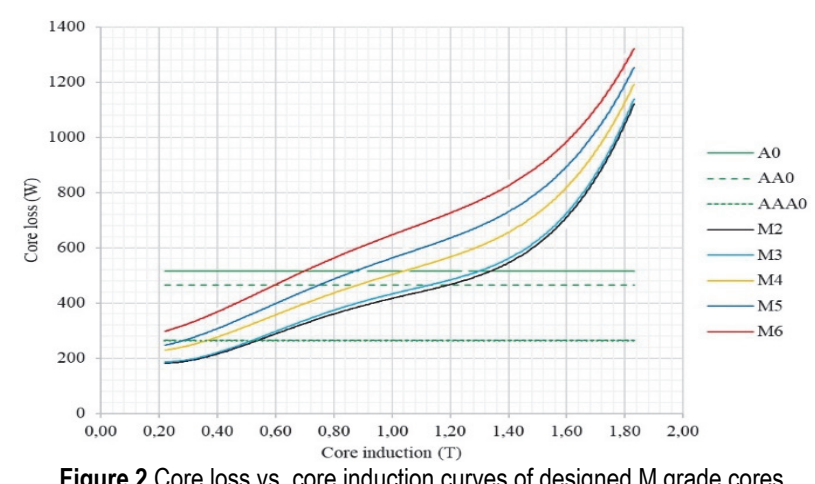

Figure 2 Core loss vs. core induction curves of designed $\mathrm{M}$ grade cores
Due to the electromagnetic characteristics, $\mathrm{H}$ grades have superior features, when compared to $\mathrm{M}$ grades. By selecting $0,23 \mathrm{~mm}$ thick $\mathrm{H} 0$ steel, which is the finest type of this grade, required core inductions were calculated as 1,37 T, 1,22 $\mathrm{T}$ and 0,54 $\mathrm{T}$ to match the necessities of A0, AA0 and AAA0 classes, respectively. For $\mathrm{H} 2$ steel, which has the equal thickness of M5, these induction values are calculated as 1,04 T, 0,91 T and 0,33 T, respectively.

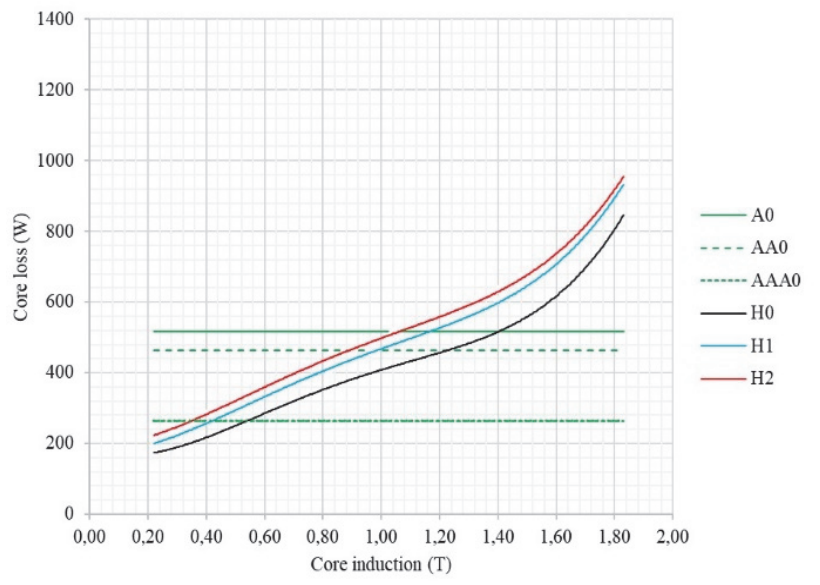

Figure 3 Core loss vs. core induction curves of designed $\mathrm{H}$ grade cores

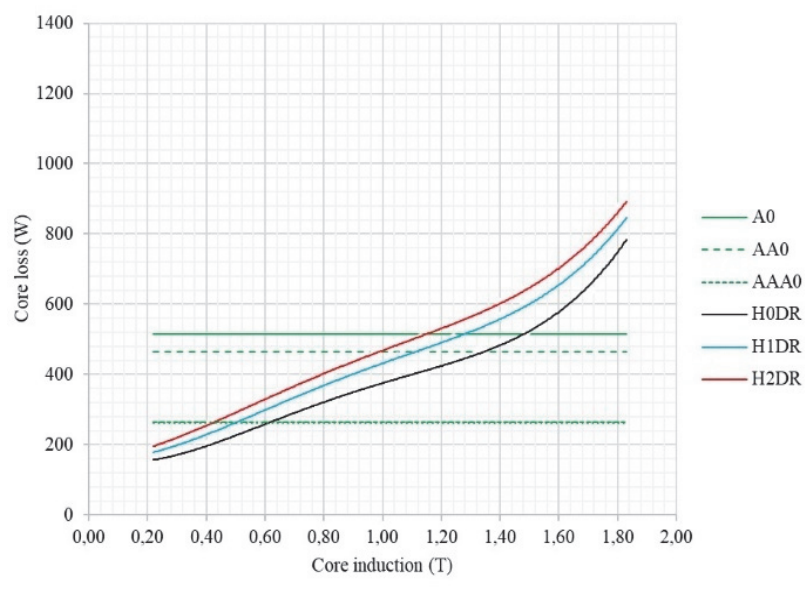

Figure 4 Core loss vs. core induction curves of designed $\mathrm{H}$-DR grade cores

By preferring H-DR grade materials, whose domain structure was improved by laser scribing process, more compact transformer designs could be possible. The superior steel type in this grade is $0,23 \mathrm{~mm}$ thick H0-DR steel, which has the same thickness as $\mathrm{H} 0$ steel. Using H0DR steel in core design, core inductions were calculated as 1,47 T, 1,31 $\mathrm{T}$ and $0,61 \mathrm{~T}$ to match the necessities of $\mathrm{A} 0$, AA0 and AAA0 loss classes, respectively.

When M5 is the only steel type used in core construction, A0 class core design is possible with the induction value of $0,89 \mathrm{~T}$. Considering all design studies between $0,25 \mathrm{~T}$ and 1,90 $\mathrm{T}$, obtaining $\mathrm{A} 0$ class core construction could be possible between $0,84 \mathrm{~T}$ and 1,41 $\mathrm{T}$ for mixed core construction. In Fig. 5, core cost vs. core induction values for mixed core design where M5 and another steel type combined, are given. No-load loss requirements of $\mathrm{A} 0$ class were met in all these core designs. 


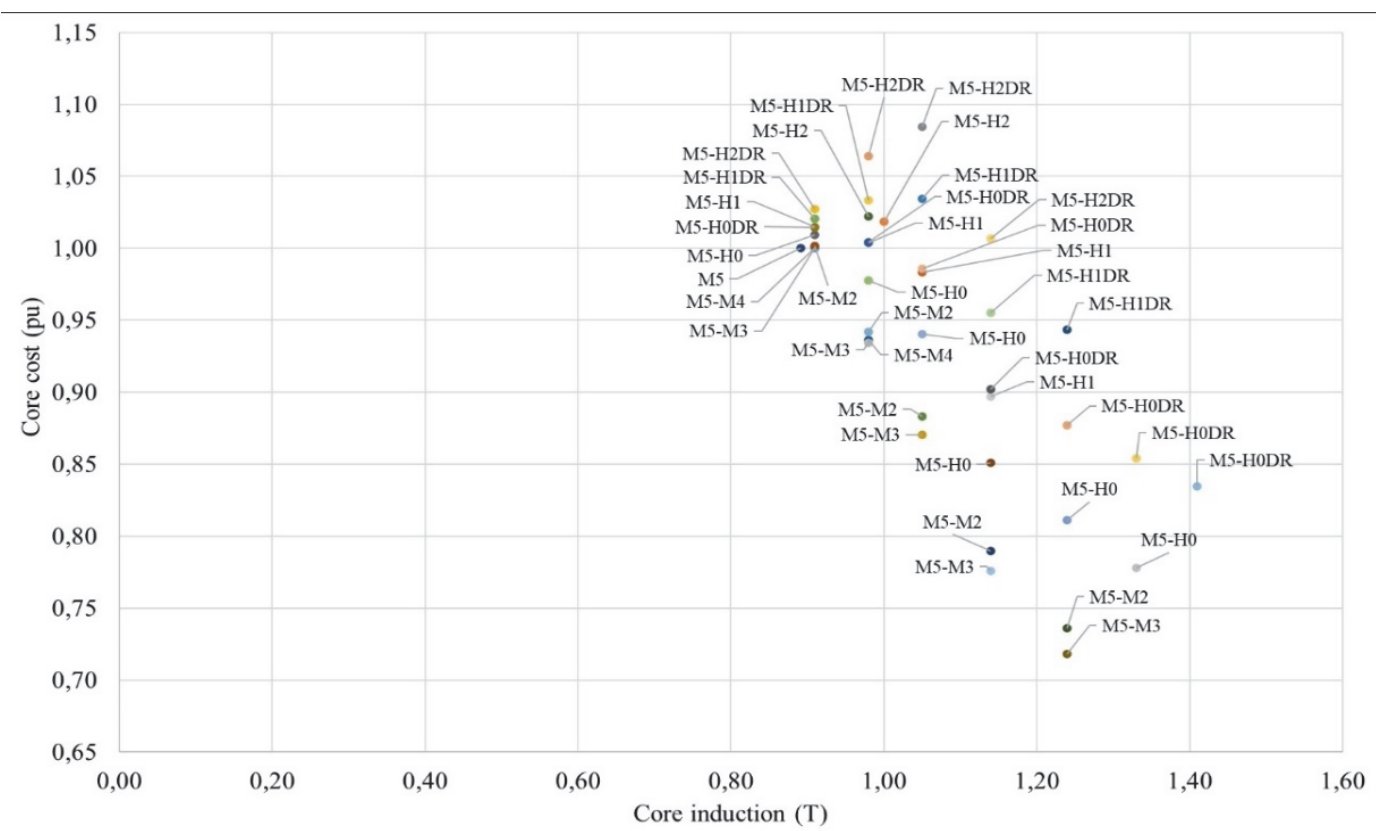

Figure 5 Cost vs. core induction values of designed mixed cores for A0 loss class

Total core weight $(\mathrm{kg})$ and unit price $(\mathrm{USD} / \mathrm{kg})$ of core materials were used in calculating the core costs for single and mixed core constructions. Unit prices of six of totally eleven steel types were directly obtained from market. For other materials, unit prices were derived depending on their loss densities. Average specific costs of $\mathrm{M}, \mathrm{H}$ and $\mathrm{H}-\mathrm{DR}$ grades were considered as 2,6 USD/kg, 3,1 USD/kg and 3,6 USD/kg, respectively.

In Fig. 5, cost of M5 core was considered as reference. Core costs, where core construction was obtained by mixing M5 and another steel, were calculated among 1,007 pu and 0,718 pu. Here, obtained M3 \& M5 mixed core design for 1,24 $\mathrm{T}$ induction value seems as the cheapest core design. Calculated cost of this core is about $28,2 \%$ less than the reference core. In this mixed construction, $73 \%$ of the core was composed of M5 steel.

Obtained results show that the smallest core design would be possible by preferring H0-DR steel for the induction of $1,47 \mathrm{~T}$, for A0 class. The cost of this core is calculated as $12,57 \%$ higher than the lowest core cost, shown in Fig. 5.

As well as the technical features, economic feasibility of core construction should also be considered in transformer design stage. In [27], it is expressed that the feasible core designs for AA0 loss class could be obtained by using $\mathrm{H}$ grades. So, mixed grade cores, where $\mathrm{H}$ grades are used together with other grades, are evaluated for mixed core designs meeting AA0 loss class requirements. According to this, it was observed that the core designs which meet the requirements of AA0 loss class were obtained for the induction values of $1,22 \mathrm{~T}, 0,99 \mathrm{~T}$ and 0,91 $\mathrm{T}$ for $\mathrm{H} 0, \mathrm{H} 1$ and $\mathrm{H} 2$ steels, respectively. Here, core cost, designed with $\mathrm{H} 0$ steel, was considered as reference. Core costs designed with $\mathrm{H} 1$ and $\mathrm{H} 2$ steels were calculated as $1,273 \mathrm{pu}$ and $1,346 \mathrm{pu}$, respectively.

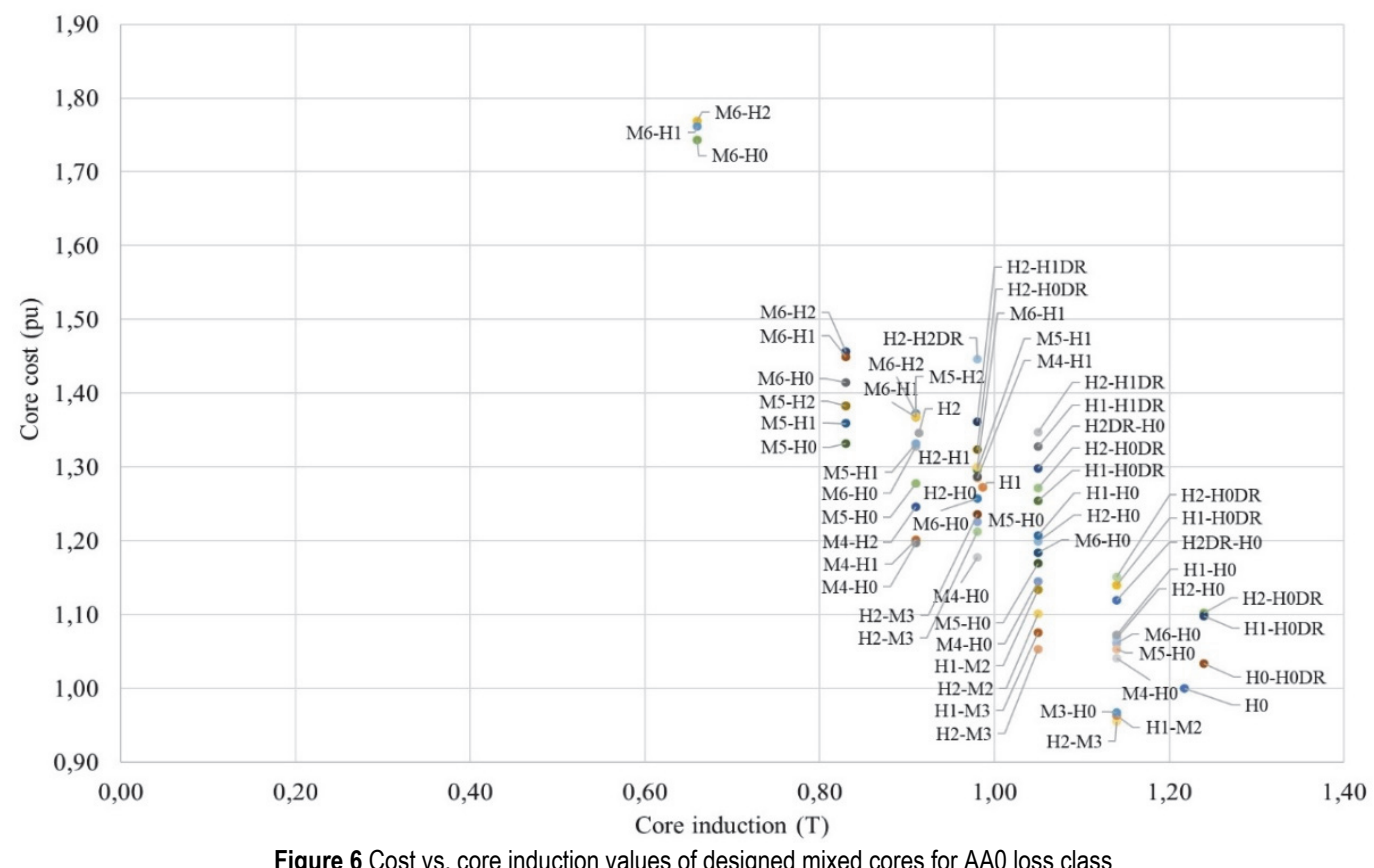

Figure 6 Cost vs. core induction values of designed mixed cores for AA0 loss class 


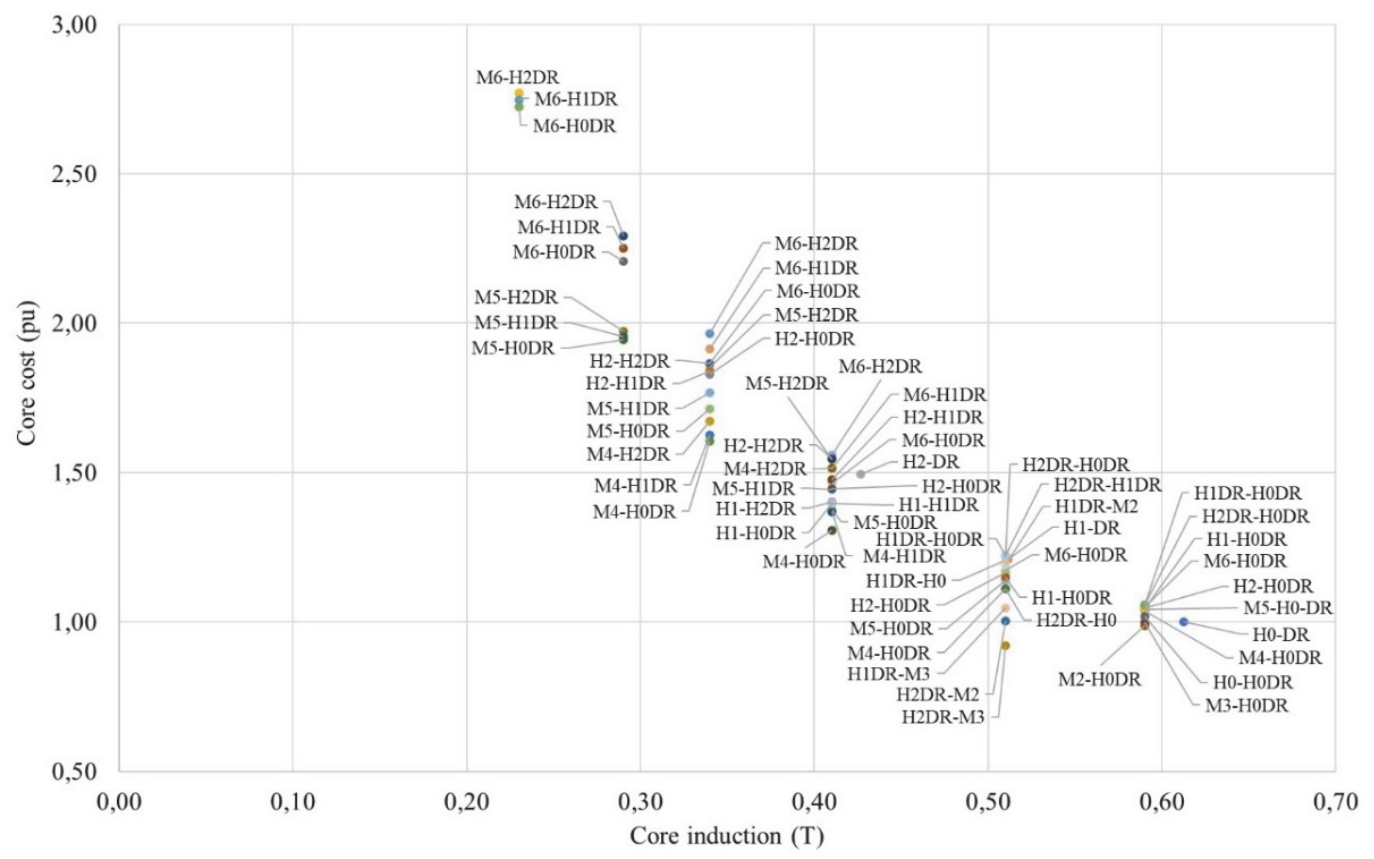

Figure 7 Cost vs. core induction values of designed mixed cores for AAA0 loss class

Fig. 6 shows the costs of mixed core designs vs. core induction that meet AA 0 class requirements, when $\mathrm{H}$ grade materials are mixed with other steel types. Accordingly, the core structure which was performed by mixing H2 \& M3 steels for $1,14 \mathrm{~T}$ induction value stands out as the most economical design. The core cost of this construction was calculated as $4,45 \%$ lower than the reference core cost.

It was determined that the most compact core design, which meets the requirements of the AA0 loss class, could be obtained when H0 \& H0-DR type steels were used together for 1,24 $\mathrm{T}$ induction value. The cost of this core is calculated as 3,39\% higher than the lowest core, shown in Fig. 6.

According to [27], H-DR is the only conventional grade type which could be considered for AAA0 class transformer design. In Fig. 7, mixed core structures in which H-DR grades were used together with other material types were evaluated for this purpose. Accordingly, it was observed that core designs which meet the requirements of the AAA0 loss class are obtained for induction values of 0,61 T, 0,51 T and 0,43 T for H0-DR, H1-DR and H2-DR type materials, respectively. Here, the core cost, designed with H0-DR material is considered as reference. Core costs designed with H1-DR and H2-DR materials are calculated as 1,208 pu and $1,495 \mathrm{pu}$, respectively.

The core structure, which is performed for the 1,14\% induction value and the H2-DR and M3 type materials used in the mixed core design, stands out as the most economical design. The core cost of this structure is calculated as $7,81 \%$ lower than the reference core cost.

It has been determined that the smallest size core design could be obtained by preferring H0-DR material for the induction of $0,61 \mathrm{~T}$, for AAA0 class. This material type is the most superior material type among core materials examined in this study.

\section{SIMULATION STUDIES}

Simulation studies are important to verify the performances of studied transformer designs created by considering different core materials and induction values. Electromagnetic analyses were carried out by using finite element method in order to determine flux distributions on core construction, core loss, load loss, short circuit reactance and induction values of the transformer. For this purpose, ANSYS Maxwell v16.1 software was used.

Among the numerical designs and mixed core structures in the previous sections, studied M5 \& H0-DR mixed core was selected in order to verify the design with simulation and prototyping studies. This core construction was designed for 1,33 $\mathrm{T}$ induction value and corresponds to the requirements of $\mathrm{A} 0$ loss class.

The transformer was modelled as a full model on a 1:1 scale. B-H and B-P curves for different core materials and parameters such as material stacking factor, thickness, permeability was obtained from the manufacturer' $\mathrm{s}$ catalogue information, separately $[22,23]$. In the modelling of the windings, copper material with electrical conductivity $\sigma=5,8.10^{7} \mathrm{~S} / \mathrm{m}$ and magnetic permeability $\mu_{r}$ $=1$ was used.

No-load analysis was performed to determine the flux density distribution and no-load losses on the core. Fig. 8 shows the flux density distribution on the core.

As the result of electromagnetic analyses, induction value of this core design was determined as $1.25 \mathrm{~T}$. Considering the flux density distribution on the core package, it is clearly seen that the flux density is not equal on the whole core. Also depending on the core construction method and shorter flux path, flux lines are concentrated on the inner corners of the core window. At these regions, observed flux densities are reached about 1,70 T, which is the highest value on the core. However, the lowest flux densities are calculated on the outer corners of the core package. This also proves that the wound core configuration instead of stacked core would be a better method for transformer construction.

Considering the flux density distributions on the core layers shown in Fig. 1, induction value of about 1,70 T causes the higher power losses at the inner layer due to this value being in the saturation zone of $\mathrm{B}-\mathrm{H}$ curve of the 
material. For this reason, while creating mixed core structure, the superior core material is preferred to apply from the inner layer of the core, called Layer-1.
By means of the electromagnetic analysis, it is possible to determine the power losses that occur in each of the layers, separately. Fig. 9 shows loss distributions occurring in the core layers for analysed mixed core construction.

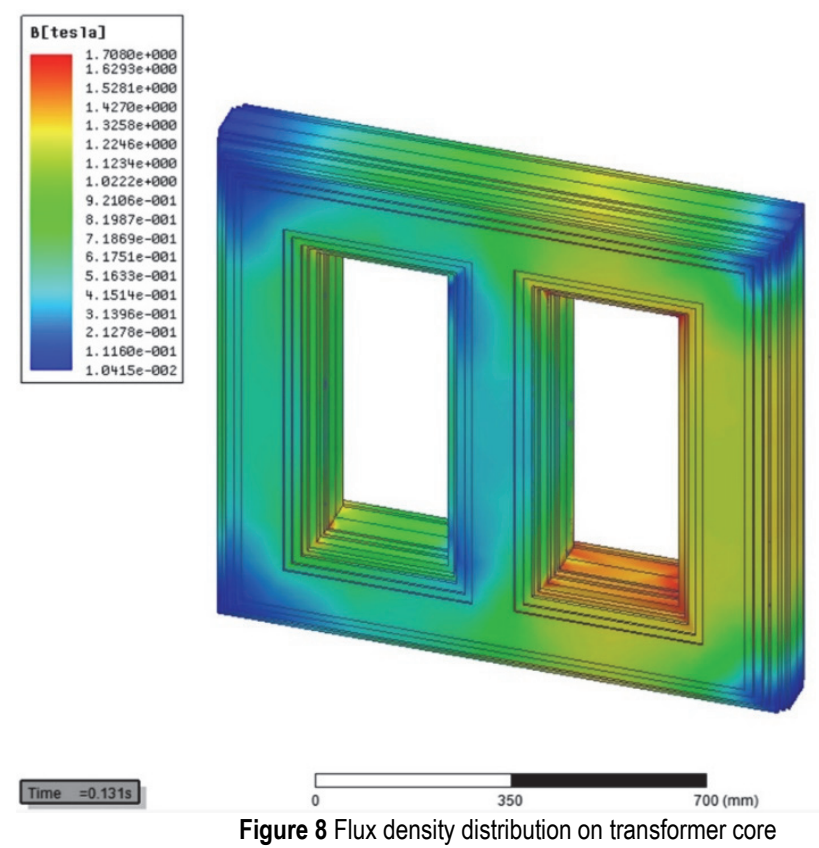

Here, Fig. 9a and Fig. 9h show the cases where the core is completely made by M5 and H0-DR type material, respectively. For these constructions, core losses were calculated as 680,03 W and 440,73 W, respectively. During the design stage, the loss values predicted by numerical calculations were obtained as $702,49 \mathrm{~W}$ and $472,65 \mathrm{~W}$ for these two materials, respectively.
When Layer-1, Layer-2 and Layer-3 are manufactured by $\mathrm{H} 0-\mathrm{DR}$ material, the core loss is calculated as 483,53 $\mathrm{W}$. This is less than the limit value of $516 \mathrm{~W}$ given for the A0 loss class. The loss value predicted at the design stage for this mixed structure is $504,11 \mathrm{~W}$. When the design and simulation results are compared, calculated relative error values are between $3,3 \%$ and $7,3 \%$, for the mixed core constructions, shown in Fig. 9.

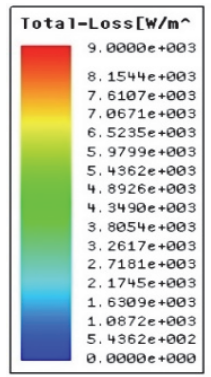

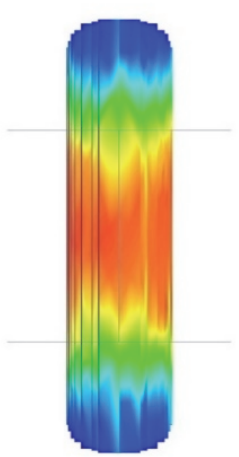

(a)

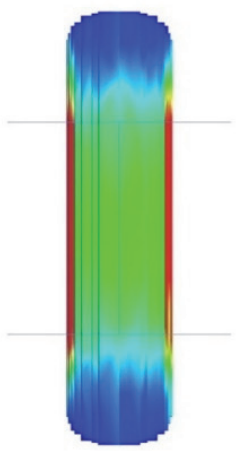

(e)

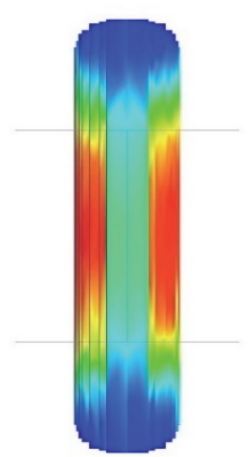

(b)

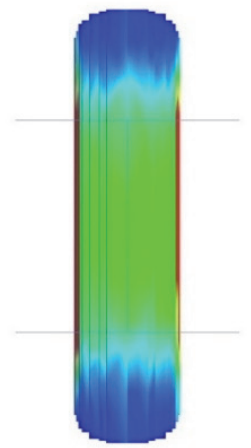

(f)

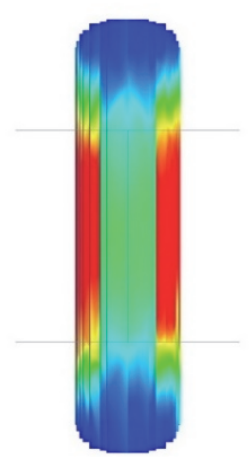

(c)

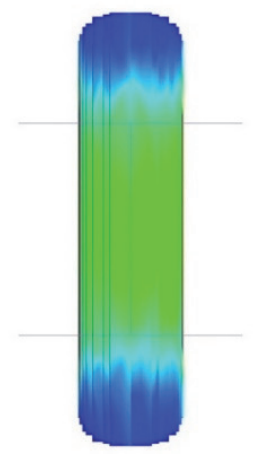

(g)

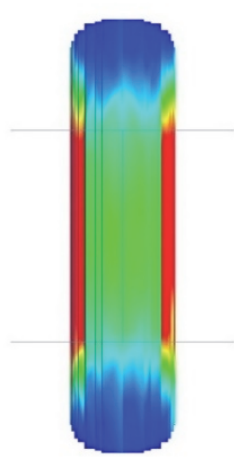

(d)

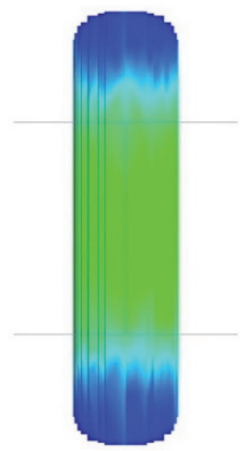

(h)

Figure 9 Variation of power loss distribution on transformer core layers depending on material type 


\section{PROTOTYPE TRANSFORMER}

Prototype mixed core transformer was manufactured, and laboratory tests were carried out. The purpose of these tests was to verify the design and analysis results and obtain the relative error between design, analysis and test results.

The core cross section of the prototype transformer manufactured is shown in Fig. 10. In accordance with the design of the core consisting of a total of seven layers, the three layers inside are manufactured using H0-DR type material and the other four layers using M5 type material. Total weight of the core is approximately $1070 \mathrm{~kg}$ and about $750 \mathrm{~kg}$ of this weight was made by H0-DR material. Multistep-lap core stacking method, which is the most used method in transformer manufacturing, has been preferred in core production. In this way, it is possible to reduce the additional losses which occur in the lamination joint areas on the flux path. According to [27], it is stated that this method preserves the applicability of transformer production in A0 loss class.

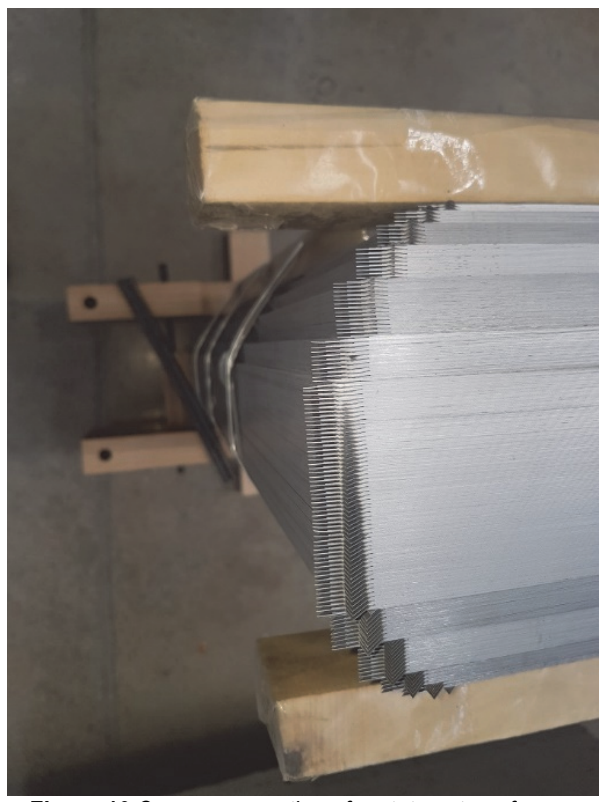

Figure 10 Core cross section of prototype transformer

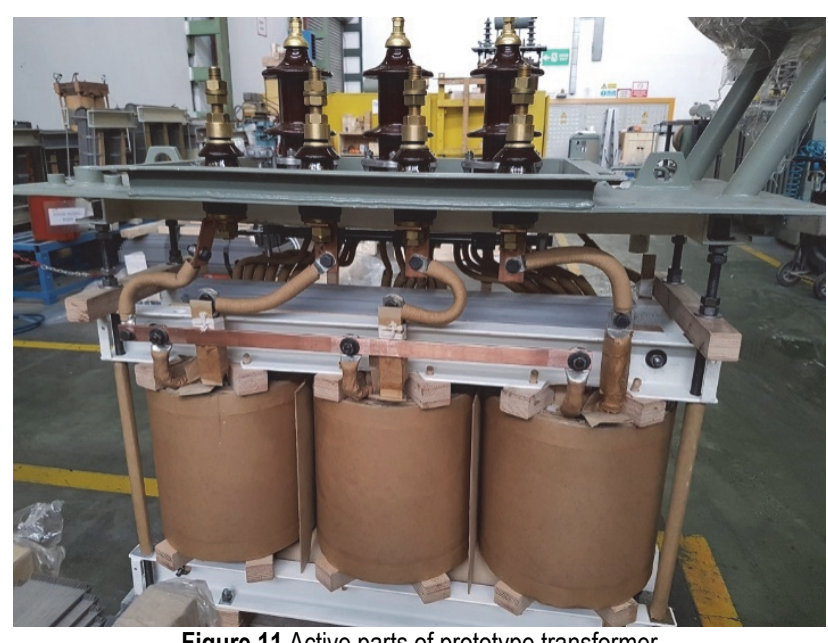

Figure 11 Active parts of prototype transformer

Active parts of the prototype transformer are shown in Fig. 11. The primary windings of the transformer were manufactured using circular copper conductors and the secondary windings were made using copper plate conductors.

Measurements of electrical parameters were carried out using an a-eberle PQ-Box 200 energy analyser, in the test laboratory of the manufacturer. Tests for determining no-load loss and load loss were performed in accordance with the requirements of IEC60076-1. Design, analysis and test results are given in Tab. 1 comparatively.

Table 1 Comparison of the design, analysis and test results of prototype

\begin{tabular}{|c|c|c|c|}
\hline & $\begin{array}{c}\text { transformer } \\
\text { loss / W }\end{array}$ & $\begin{array}{c}\text { Load } \\
\text { loss / W }\end{array}$ & $\begin{array}{c}\text { Short circuit } \\
\text { reactance / \% }\end{array}$ \\
\hline Numerical design & 504,11 & 2345,4 & 4,354 \\
\hline Electromagnetic analysis & 483,53 & 2492,2 & 4,471 \\
\hline Test \& Measurement & 508,71 & 2318,5 & 4,370 \\
\hline
\end{tabular}

Obtained no-load loss, load loss and short circuit reactance values are compared here. These are three of the main parameters, which should be carefully considered in the design stage of the transformer.

For all three parameters, it is observed that the numerical design results and measurement results are greatly matched. Obtained relative error values between design and measurement results are not more than $1,2 \%$ for three parameters given above. Therefore, it could be said that the applied numerical design procedures are greatly effective.

However, when the electromagnetic simulation and analysis results were taken into consideration, relative errors for the parameters given in Tab. 1 were calculated as $5 \% ; 7,5 \%$ and $2,3 \%$, respectively.

These differences occurred by several modelling issues. While the core was being modelled, joint regions between the steel laminations were neglected. These regions cause irregular flux distributions, which results in additional power losses in the core. Similarly, used threedimensional model of the windings also affects the calculated load loss value. Both primary and secondary windings are modelled as coarse solid windings instead of fine turn-by-turn modelling. This increases the calculated relative error in load loss. Using more detailed model both in the core and the windings would decrease error values but also increase solution time and required microprocessor and memory capacity. In addition, due to minor variations in winding dimensions that occurred in manufacturing stage, the obtained short circuit reactance values also show difference.

\section{CONCLUSIONS}

It is possible to design distribution transformers in accordance with the loss classes specified in EN50588-1 in many ways depending on the selected design parameters. However, it is also desired to present the final design both as economically and commercially feasible, as possible, by the manufacturers. For this purpose, core losses are one of the important parameters.

In design stage, selecting low cost materials leads to the core volume reaching very large values and the total core cost to increase. Although, the core dimensions could be reduced with the use of materials with high electrical 
performance, the high unit costs of these materials also increase the total core cost.

The results obtained in this study show that the use of mixed Si-Fe materials in core design significantly affects both core dimensions and total core cost. Material types to be mixed in core construction may vary depending on their unit prices. However, obtained results prove that it is possible to obtain mixed core designs more economically than the single steel cores where superior material types are used.

Due to the absence of a uniform flux distribution on the core, it is one of the most important factors to identify the layers with high flux density in the core by electromagnetic analysis studies at the design stage.

By selecting superior steel types in these layers, which provide lower specific loss, more compact cores could be obtained. On the other hand, total core cost could be decreased by preferring high specific loss materials in the layers with lower flux densities. Obtained results in design, simulation and experimental stages of this study prove the feasibility of mixed core structures in both technical and economical manner.

\section{REFERENCES}

[1] Johannesen, S. E. (1929). Electrical induction apparatus. US Patent 1698 634, Jan. 8.

[2] McRell, H. F. (1929). Magnetic core. US Patent 1731861.

[3] Troy, M. O. (1931). Magnetic core for electrical apparatus. US Patent 1805 534, 19.

[4] Granfield, J. C. (1946). Magnetic core. US patent 2465798 , March 28.

[5] Kwiczala, J. \& Kasperczyk, B. (2007). Composite cores in current transformers. 16th International Conference on Composite Materials, Kyoto-Japan, 1-5.

[6] Lesniewska, E. \& Rajchert, R. (2010). Application of the field-circuit method for the computation of measurement properties of current transformers with cores consisting of different magnetic materials. IEEE Transactions on Magnetics, 46, 3778-3782. https://doi.org/10.1109/TMAG.2010.2050068

[7] Mohan, M. \& Singh, P. K. (2012). Distribution transformers with amorphous-CRGO core: an effort to reduce the cost of aamorphous core distribution transformer. ARPN Journal of Engineering and Applied Sciences, 7, 680-685.

[8] Işık, F. \& Uyaroğlu, Y. (2015). Amorphous core transformers efficiency analysis in Turkish electrical distribution system. Turkish Journal of Electrical Engineering \& Computer Sciences, 23(6), 1523-1535. https://doi.org/10.3906/elk-1401-195

[9] Kurita, N., Nishimizu, A., Kobayashi, C., Tanaka, Y., Yamagishi, A., Ogi, M., Takahashi, K., \& Kuwabara, M. (2018). Magnetic properties of simultaneously excited amorphous and silicon steel hybrid cores for higher efficiency distribution transformers. IEEE Transactions on Magnetics, 54(11), 1-4. https://doi.org/10.1109/TMAG.2018.2835498

[10] Magdaleno-Adame, S., Melgoza-Vazquez, E., OlivaresGalvan, J. C. \& Escarela-Perez, R. (2016). Loss reduction by combining electrical steels in the core of power transformers. International Transactions on Electrical Energy Systems, 26, 1737-1751. https://doi.org/10.1002/etep.2175

[11] Kefalas, T. D. \& Kladas A. G. (2014). Reduction of Cost and Losses of Transformers by Using Composite Magnetic Cores. International Conference on Electrical Machines, Berlin-Germany, 2257-2263. https://doi.org/10.1109//CELMACH.2014.6960499
[12] Kefalas, T. D. (2009). Transformers Made of Composite Magnetic Cores: An Innovative Design Approach. Recent Patents on Electrical Engineering, 2, 1-12. https://doi.org/10.2174/1874476110902010001

[13] Georgilakis, P. S. (2009). Differential evolution solution to transformer no-load loss reduction problem. IET Generation, Transmission \& Distribution, 3(10), 960-969. https://doi.org/10.1049/iet-gtd.2009.0184

[14] Haidar, A. M. A. \& Al-Dabbagh, M. (2013). The influences of T-joint core design on no-load losses in transformers. IEEE Potentials, 32(3), 40-48. https://doi.org/10.1109/MPOT.2012.2211911

[15] Binns, D. F., Crompton, A. B., \& Jabensari, A. (1986). Economic design of a $50 \mathrm{kVA}$ distribution transformer Part 2: Effect of different core steels and loss capitalisations. IEE Proceedings, 133(7), 451-456. https://doi.org/10.1049/ip-c.1986.0068

[16] Cinar, M. A., Alboyac1, B., \& Sengul, M. (2014). Comparison of Power Loss and Magnetic Flux Distribution in Octagonal Wound Transformer Core Configuration. Journal of Electrical Engineering and Technology, 9(4), 1290-1295. https://doi.org/10.5370/JEET.2014.9.4.1290

[17] Kefalas, T. D. \& Magdaleno-Adame, S. (2018). Technoeconomic comparative evaluation of mixed and conventional magnetic wound cores for three-phase distribution transformers. Electric Power Systems Research, 155, 331339. https://doi.org/10.1016/j.epsr.2017.11.003

[18] Pfützner, H., Shilyashki, G., Hamberger, P., Aigner, M., Hofbauer, F., Palkovits, M., Trenner, G., Gerstbuer, E., Matkovic, I., \& Galaboy, V. (2014). Automatic 3-D Building Factor Analyses of a Grain-Oriented Model Transformer Core. IEEE Transactions on Magnetics, 50(4), 1-4. https://doi.org/10.1109/TMAG.2013.2287607

[19] Popescu, M., Miller, T. J .E., McGilp, M., Ionel, D. M., Dellinger, S. J. \& Heidemann, R. J. (2007). On the physical basis of power losses in laminated steel and minimum-effort modeling in an industrial design environment. IEEE Industry Applications Annual Meeting, Louisiana-USA, 60-66. https://doi.org/10.1109/07IAS.2007.14

[20] Broddefalk, A. \& Lindenmo, M. (2006). Dependence of the power losses of a non-oriented 3\% Si-steel on frequency and gauge. Journal of Magnetism and Magnetic Materials, 304(2), 586-588. https://doi.org/10.1016/j.jmmm.2006.02.183

[21] Mthombeni, T. L. \& Pillay, P. (2006). Physical basis for the variation of lamination core loss coefficients as a function of frequency and flux density. 32nd IEEE Annual Conference on Industrial Electronics, Paris-France, 1381-1387. https://doi.org/10.1109/ıecon.2006.347545

[22] AK Steel Product Data Bulletin. (2007). Selection of Electrical Steels for Magnetic Cores. Ohio, USA.

[23] AK Steel Product Data Bulletin. (2013). TRAN-COR H Grain Oriented Electrical Steels, Ohio, USA.

[24] Adame, S. M., Vazquez, E. M., Galvan, J. C. O., \& Perez R. E. (2016). Loss reduction by combining electrical steels in the core of power transformers. International Transactions on Electrical Energy Systems, 26(8), 1737-1751. https://doi.org/10.1002/etep.2175

[25] Dawood, K., Alboyaci, B., Cinar, M. A., \& Sonmez, O. (2017). A new method for the calculation of leakage reactance in power transformers. Journal of Electrical Engineering and Technology, 12(5), 1883-1890. https://doi.org/10.5370/JEET.2017.12.5.1883

[26] EN50588-1 (2017). Medium power transformers $50 \mathrm{~Hz}$ with highest voltage for equipment not exceeding $36 \mathrm{kV}$ - Part 1: General equipments, International Standard.

[27] Çınar, M. A. (2020). Investigation of the Economical and Technical Design Feasibility of Si-Fe Graded Distribution Transformers according to EN50588-1. Pamukkale University Journal of Engineering Sciences, 26(2), 1-9. https://doi.org/10.5505/pajes.2019.24306 
Contact information:

Mehmet Aytac CINAR, PhD

Izmit Vocational School,

Kocaeli University,

Kartepe, Kocaeli, Turkey

E-mail: aytac@kocaeli.edu.tr 